\title{
Rumo à Economia Circular: Sinergia Existente entre as Definições Conceituais Correlatas e Apropriação para a Literatura Brasileira
}

\author{
Simone Sehnem e Susana Carla Farias Pereira
}

\section{RESUMO}

A economia circular aumentou a sua capacidade de atrair a atenção de pesquisadores, gestores e governos. A disseminação do conceito, por vezes, está associada ao uso de alguns termos técnicos da nova revolução industrial como sendo sinônimos. Mas realmente são sinônimos? São complementares? São práticas diferentes? Para ajudar a esclarecer essa confusão de conceitos que ocorre tanto na academia quanto na prática empresarial, este artigo apresenta diretrizes conceituais sobre importantes termos relacionados à economia circular. O objetivo do estudo consiste em esclarecer as diferenças semânticas e conceituais dos termos: economia circular, economia espiral, cradle to cradle, double loop, closed-loop, logística reversa, análise do ciclo de vida, upcycle e simbiose industrial. A contribuição do estudo está alicerçada na categorização da literatura sobre o tema economia circular e seus termos correlatos, assim como na proposição de traduções para termos clássicos da área de operações. Compreender as definições conceituais e suas origens é essencial para desenvolver o conhecimento na área, bem como a sua difusão.

Palavras-chave: economia circular; cradle to cradle; closed-loop; double loop; análise do ciclo de vida; simbiose industrial.

Towards the Circular Economy: Existing Synergy Among the

\section{ABSTRACT}

Circular economy has increasingly attracted attention of researchers, managers and governments. The dissemination of the concept is sometimes associated with the use of some technical terms of the new industrial revolution as being synonyms, but are these terms synonyms, complementary or do they just express different practices? To help clarifying these misunderstandings that occur in both academia and business practice, this paper presents conceptual guidelines on important terms of circular economy. The purpose of the study is to clarify the semantic and the conceptual differences of the terms: circular economy, spiral economy, cradle to cradle, double loop, closed loop, reverse logistics, life cycle analysis, upcycle and industrial symbiosis. The study is based on a categorization of Circular Economy literature and their related terms and translations for classic terms of management operations. Understanding the conceptual definitions and their origins is essential for developing knowledge in the area, as well as to disseminate such knowledge.

Keywords: circular economy; cradle to cradle; closed-loop; double loop; life cycle analysis; industrial symbiosis.

Recebido em: 30/10/2017

Aprovado em: 01/02/2018 Última Modificação: 08/10/2018

Check for updates

Simone Sehnem (D), Professora do Mestrado Profissional e Doutorado Acadêmico em Administração, Universidade do Oeste de Santa Catarina, Brasil. Professora do Mestrado em Administração, Universidade do Sul de Santa Catarina, Brasil.

Doutorado em Administração, Universidade do Vale do Itajaí, Brasil.

simonesehnem_adm@yahoo.com.br

\section{Susana Carla Farias}

Pereira (iD,

Escola de Administração de Empresas de São Paulo, Fundação Getúlio Vargas, Brasil.

Doutorado em Administração de Empresas pela Fundação Getúlio Vargas São Paulo, Brasil.

susana.pereira@fgv.br 


\section{Introdução}

Aeconomiacircular propõeque ovalor dos recursos extraídos e produzidos seja mantido em circulação por meio de cadeias produtivas integradas. O destino de um material deixa de ser uma questão de gerenciamento de resíduos, mas parte do processo de design de produtos e sistemas (Webster, 2015). A ideia é eliminar o conceito de lixo e enxergar cada material dentro de um fluxo cíclico, possibilitando a trajetória dele 'do berço ao berço' - de produto a produto, preservando e transmitindo seu valor. (Webster, 2015). O aproveitamento inteligente dos recursos que já se encontram em uso no processo produtivo possibilita que o crescimento econômico não fique exclusivamente dependente do consumo crescente de novos recursos. A criação de sistemas de reparo, reuso e remanufatura, além de uma reciclagem efetiva, permite que matérias-primas introduzidas em cadeias de produção mantenham ou mesmo aumentem seu valor. Portanto, a economia circular é um sistema industrial intencionalmente reparador ou regenerativo, que traz benefícios operacionais e estratégicos, bem como um enorme potencial de inovação, geração de empregos e crescimento econômico. Ademais, possui o objetivo de manter produtos, componentes e materiais em circulação para tirar o máximo de valor e utilidade, através da distinção entre ciclos técnicos e biológicos (Webster, 2015; EMF, 2013).

O campo interdisciplinar da economia circular tem crescido nos últimos anos com o interesse da indústria, academia e governos. Associado ao trabalho efetuado pela Ellen MacArthur Foundation de disseminação do conceito de economia circular nos diferentes continentes(EMF, 2017), são várias as iniciativas de diretrizes federais existentes na Europa e Ásia: a visão WRAP's para a economia circular do Reino Unido até 2020 (http://www.wrap. org.uk/content/wraps-vision-uk-circular-economy-2020 recuperado em 7 de dezembro de 2017), rumo a uma economia circular em Portugal (https:// www.circulareconomy.pt/ recuperado em 7 de dezembro de 2017); exemplos de simbiose industrial, como na Zona de Desenvolvimento Econômico e Tecnológico de Rizhao, China, promovidos pela agência de planejamento do país, Comissão Nacional de Desenvolvimento e Reforma (NDRC) e órgãos como o Ministério da Proteção Ambiental; as iniciativas da Holanda, Escócia, Suíça, Japão, Dinamarca e tantos outros países que estão comprometidos com a circularidade de recursos (https://www.ellenmacarthurfoundation. org/news/circular-economy-implementation-in-china recuperado em 7 de dezembro de 2017).

Associado ao crescimento e interesse pelo tema, estudos anteriores destacam que a confusão semântica e a falta de foco em questões sociais na economia circular demandam maiores discussões e avaliações do conceito (Murray, Skene, \& Haynes, 2017). Este artigo tem como objetivo esclarecer as diferenças semânticas e conceituais entre o termo economia circular e os termos economia espiral, cradle to cradle, double loop, closed-loop, logística reversa, análise do ciclo de vida, upcycle e simbiose industrial. Dessa forma, este estudo apresenta uma visão geral dos diferentes conceitos que, na maioria das vezes, são veiculados em discursos de empresários, governantes e cientistas acadêmicos no contexto da economia circular. 
A revisão teórica do estudo foca na definição conceitual, origem e disseminação dos conceitos correlatos à economia circular. Finaliza com a proposta de um framework que apresenta as interfaces existentes entre cada um dos termos contemplados neste estudo, suas premissas e os benefícios sustentáveis obtidos pelas organizações a partir da adoção dessas práticas organizacionais nos seus ambientes de produção.

Portanto, não se trata de uma revisão sistemática de literatura, mas de um esclarecimento conceitual. O processo de construção do artigo se deu por meio do acesso à base de dados Scopus, considerada a mais completa existente no mercado. Assim sendo, introduziram-se um a um os termos-chave: economia circular, economia espiral, cradle to cradle, double loop, closed-loop, logística reversa, análise do ciclo de vida, upcycle e simbiose industrial. Os termos compostos foram buscados entre aspas. Além disso, os dez primeiros artigos foram selecionados por ordem de relevância de cada assunto. A partir desses textos, iniciou-se a leitura e mapeamento de outros artigos citados nesses textos pré-selecionados e que remetiam ao esclarecimento conceitual dos termos em análise. Encerrou-se a busca de novos textos quando foi possível identificar os elementos básicos que permitiam explicar a origem dos diferentes termos pesquisados.

\section{Origens conceituais}

Esta seção descreve as premissas encontradas na literatura e que se alinham com a origem dos conceitos em análise: economia circular, economia espiral, cradle to cradle, double loop, closed-loop, logística reversa, análise do ciclo de vida, upcycle e simbiose industrial.

\section{Economia circular}

O termo economia circular aparece na literatura em diferentes áreas de conhecimento. Cada área atribui a origem do conceito a um pesquisador em específico. O princípio da economia circular não é novo e aparece em 1848, quando R.W. Hofman, primeiro presidente da Royal Society of Chemistry, declarou: “... em uma fábrica de produtos químicos ideal, não há nenhum desperdício, mas apenas produtos. Quanto melhor uma fábrica real faz uso de seus resíduos, quanto mais se aproxima de seu ideal, maior é o lucro" [transcrição livre]. (Lancaster 2002; Murray; Skene \& Haynes, 2017).

A preocupação com os limites do crescimento e a escassez de recursos no pensamento econômico remontam a Malthus e Ricardo, ressurgindo na década de 1960, quando foi publicado o livro Primavera Silenciosa, isto é, Silent Spring em sua obra original, de Rachel Carlson (1962) e, em seguida, com Ken Boulding (1966), no ensaio "A economia da terra da nave espacial" [transcrição livre]. Nesse artigo, Boulding defendia que o homem precisa encontrar o seu lugar num sistema ecológico cíclico capaz de reproduzir continuamente formas materiais desde que haja a necessária entrada energética. $\mathrm{O}$ autor também cita essas fontes de energia, água e materiais, para argumentar que os futuros sustentáveis são construídos por meio da reutilização e reciclagem de materiais. Essa definição foi retomada 
por Georgescu-Roegen (1971), que afirmava que o sistema econômico deve envolver o uso máximo de energias renováveis e de reciclagem. Esses argumentos são a base da economia ecológica, um campo em que a metáfora circular continua a prevalecer.

O campo da ecologia industrial tem suas origens no trabalho idealizado por Frosch e Gallopoulos (1989), que desenharam analogias com materiais e fluxos de energia em ecossistemas naturais, a fim de argumentar que os meios para gerar o desenvolvimento sustentável ocorrem via ciclo de materiais e através da troca de subprodutos e resíduos. Em tal caminho, eles argumentaram que as economias deixam de ser lineares, tornando-se circulares. Paralelo a esse, outro trabalho (Bras \& Mcintosh, 1999) começou a aplicar o conceito do ciclo de vida a objetos manufaturados. Ideias sobre o prolongamento da vida do produto, mediante a reparação e recondicionamento de produtos, por meio da remanufatura, foram pela primeira vez citados por Robert Lund, no final de 1970, e início de 1980 conforme destacaram Bras e Mcintosh (1999), bem como em um paper publicado em 1982 por Walter Stahel, que agora aparece com destaque no trabalho da Ellen MacArthur Foundation sobre a economia circular. Estender o ciclo de vida do produto era visto como um meio de prevenção de resíduos e como chave à transição para modos sustentáveis de produção e consumo (Cooper, 2005; 2010).

O conceito de economia circular surgiu recentemente como uma meta política, em um contexto de aumento dos preços dos recursos e mudanças climáticas. Num modelo econômico circular, os resíduos tornam-se recursos a serem recuperados e revalorizados por meio da reciclagem e reutilização (Gregson, Crang, Fuller, \& Holmes, 2015). É uma alternativa para melhorar a eficiência do uso de materiais e energia. Seu termo foi empregado pela primeira vez por dois economistas ambientais da Grã-Bretanha - Pearce e Turner no ano de 1990. Os autores editaram o livro Economia dos Recursos Naturais e do Meio Ambiente no qual destacaram que a economia tradicional foi desenvolvida sem a pretensão de construir tendências de reciclagem e de tratar o meio ambiente como um reservatório de resíduos. Atualmente, há a necessidade de contemplar a Terra com um sistema econômico fechado, em que a economia e o meio ambiente não são caracterizados por interligações lineares, mas por uma relação circular. Dessa forma, é possível obter uma relação ganha-ganha à economia e ao meio ambiente. Nesse sentido, Pearce, \& Turner (1990) propuseram um ciclo fechado de materiais na economia (Su, Heshmati, \& Geng, 2013).

O precursor na implantação do conceito de economia circular foi a Alemanha, no ano de 1996, mediante a aprovação de uma lei de gestão das substâncias tóxicas e a gestão de resíduos em ciclo fechado. Em seguida, o Japão promulgou uma lei, no ano de 2000, para promover a economia circular em nível nacional. O governo japonês estimulou o surgimento de uma sociedade de alta produção, de alto consumo e desperdício para desenvolver um projeto- piloto voltado à economia circular. A execução permitiu transformar o espaço em uma sociedade orientada à reciclagem (Zang, 2006). Uma característica comum da economia circular retratada por esses dois países é evitar a deterioração do meio ambiente e promover a conservação dos recursos escassos por meio de uma gestão eficaz dos 
resíduos, em especial, a gestão de resíduos sólidos. Por conseguinte, é uma política de gestão ambiental para melhoria de forma incremental da gestão dos recursos usados nas cadeias de produção (Su, Heshmati, \& Geng,2013).

$\mathrm{Na}$ China, por sua vez, a economia circular foi introduzida como sendo um novo modelo de desenvolvimento a fim de tornar a estrutura econômica chinesa mais sustentável (Geng \& Doberstein,2010). O foco principal da economia circular preconizado no seu conceito de origem, de primar pela reciclagem dos resíduos, passou a ser direcionado a um amplo controle orientado à eficiência ao longo dos fluxos de produção e criação de circuitos fechados dos materiais em todas as fases de produção, distribuição e consumo. A ênfase da economia circular passou a englobar: gestão de resíduos e escassez de recursos; eficiência energética e de conservação; manejo da terra e proteção do solo; problemas de gestão de recursos hídricos integrados (Su et al., 2013). A China incorporou a economia circular nos seus 11. e 12: planos quinquenais como base do futuro crescimento econômico do país. Essa priorização do tema tem dado visibilidade à economia circular no Ocidente.

No Reino Unido, também há diversas iniciativas, por exemplo, o documento Making Thinks Last: a circular economy strategy for Scotland, Securing the future - The role of resource efficiency do Reino Unido, homologados pelo governo local no ano de 2010 e 2016, respectivamente. O Parlamento Europeu também publicou, no ano de 2017, um plano de ação à implantação da economia circular.

Alguns autores (Jacobsen, 2006; Yuan, Bi, \& Moriguichi, 2006) afirmam que o conceito adotado pela China apresenta similaridade com o conceito de ecologia industrial que enfatiza os benefícios da adoção da gestão de resíduos sólidos, incluindo energia, água e diferentes subprodutos, assim como informações. Esses autores citam como exemplo a simbiose industrial, na qual os benefícios coletivos são oriundos de aspectos econômicos e de aspectos ambientais. Por outro lado, Gregson et al. (2015) compreendem que o conceito de economia circular se situa em áreas afins, mas distintas da economia ecológica e ambiental.

A mudança chave da economia circular, no entendimento de Alexander e Reno (2012), é ver a natureza não como uma externalidade sem custos, mas como um conjunto de ações, recursos potenciais, fluxos e serviços que podem ser medidos e aos quais podem ser atribuídos valores. Vários métodos e ferramentas têm sido desenvolvidos para mensurar os materiais e os fluxos de energia, incluindo análise do ciclo de vida, análise de fluxo de materiais e contabilidade triple bottom line (Gregson et al., 2015). A economia circular, ao contrário da linear, é um modelo que preza produzir valor sem destruir a natureza, assim como restaurar e proteger. "Circular" remete também à ideia de ciclo e há dois tipos de ciclo a considerar: os ciclos bioquímicos (como o ciclo da água por exemplo) e os ciclos técnicos (relacionados com a reciclagem dos materiais). Sua implementação acontece em vários níveis. Primeiro, ao nível da empresa, no que diz respeito à conversão dos seus processos produtivos em práticas mais limpas. Segundo, ao nível interempresarial (sendo aqui muito importante mencionar o conceito de simbiose industrial, que inclui práticas como a partilha de infraestruturas 
e a reutilização de resíduos de uma empresa por outra que os converte em recursos). Terceiro, ao nível do município ou entidade territorial, com a colaboração entre diversos agentes - empresariais e governativos (https:// www.circulareconomy.pt/ recuperado em 7 de dezembro de 2017).

O modelo de economia circular, conforme EMF (2017), possui quatro ciclos técnicos: a) Manutenção do produto; b) Reutilização/redistribuição produto usado; c) Atualização/remanufatura do produto e d) Reciclagem de produto. No ciclo menor, o produto/material retém o valor mais alto, já que pode ser aplicado mais vezes, de acordo com sua finalidade original. No ciclo de maior tempo, o valor residual do produto é mais baixo. Além disso, o modelo de economia circular apresenta quatro estágios importantes, nos quais as empresas precisam se engajar para aderirem à economia circular:

a. design do produto: implica melhorias na escolha dos materiais e design de produtos. Tais mudanças incluem padronização e modularização de componentes, fluxos de material puro e design para desmontagem direta. A implementação dessas estratégias faz com que o processo de produção das organizações se torne mais eficiente. Qual é o custo real do produto? Qual é o valor dos fluxos residuais e como ocorrem? Os fluxos residuais são usados para produtos novos ou outros? Como o produto deve ser transportado, embalado e comercializado? Como o processo de produção pode ser otimizado em termos ecológicos e econômicos? Qual é o ciclo de vida do produto? Esse ciclo será ampliado? Quais materiais devem ser excluídos no design do produto, não só de uma perspectiva funcional, mas também em termos de saúde e outros aspectos indiretos? Como os materiais podem ser facilmente identificados ou rotulados em termos de reciclagem futura? Como o produto pode ser dissimulado facilmente para reutilizar diferentes componentes ou reciclar mono materiais?

b. modelos de negócios: concentram-se em modelos de negócios inovadores, mais especificamente mudando a propriedade para ganhos no desempenho, o que oferece instrumentos para traduzir produtos projetados com o intuito de reutilizá-los em proposições de valores atraentes. Essa perspectiva exige que os fabricantes pensem diferentemente sobre produtos e assumam a responsabilidade pelos produtos durante o ciclo de vida. A questão é sempre como os produtos usados podem tornar-se valiosos novamente. Quais modelos de negócios são adequados para esse produto? O produto pode ser oferecido como um serviço em vez de ser vendido como um produto? Quais opções de otimização estão disponíveis para colaboração em setores ou cadeias de produção (aquisição, transporte, intercâmbio de serviços públicos como energia residual, calor, materiais, água e espaço)? Como a logística reversa pode ser organizada ou garantida? Como os fluxos de valor (social, natural e/ou econômico) podem ser traduzidos para permitir uma melhor rastreabilidade dos benefícios da economia circular?

c. Redes reversas globais: o foco está no ciclo do usuário ao fabricante. Entre outros, faz alusão à responsabilidade do fabricante citado 
sob condições de habilitação. Isso inclui, por exemplo, devolver obrigações de aceitação, logística reversa e outros sistemas. Essa reversão pode ser expandida em uma escala internacional, permitindo a reintrodução de materiais em produtos exportados como resíduos. O objetivo das redes reversas é ter fabricantes ou terceiros como partes que prestam serviços compartilhados e coletam materiais eficientemente. Quais redes podem ser implantadas? (por exemplo, Oogstkaart.nl e reciclagem de terceiros). Como os fluxos do produto podem ser retornados para a base, via mecanismos reversos que precisam ser formalizados?

d. Condições de habilitação: centram-se nas condições que permitem a sociedade aplicar os princípios circulares. A aplicação de princípios circulares exige mais transparência em fluxos de materiais, alinhando incentivos e determinados padrões industriais. Financiamento, gerenciamento de riscos, legislação, infraestrutura e educação devem facilitar a transição. Além da mudança mecânica, é necessário desenvolver a consciência geral do consumidor para facilitar a implementação de inovação circular. As empresas também devem ser trazidas em contato intersetorial (agrupamento ecológico) e precisam estar dispostas a compartilhar informações de mercados gerais e confidenciais. A legislação ou subsídio pode ser usado para encorajar a reutilização de materiais existentes? Como a diversidade dentro da economia pode ser alavancada para a prova futura do processo de produção? Quais aspectos legais e econômicos têm impacto ao fazer o processo primário circular? Pode uma responsabilidade mais extensa do fabricante ser um gatilho para um uso mais circular de materiais?

Independentemente da origem do termo, a economia circular contém ideias oriundas de diferentes escolas de pensamento, sendo possível traçar as suas raízes até o século XVIII e as primeiras teorias econômicas surgidas naquele período. Mais recentemente, Mathews e Tan (2011, p. 436) sugeriram que "o objetivo das eco iniciativas é, eventualmente, estabelecer uma chamada economia circular, ou o que também é conhecido como uma economia de circuito fechado", enquanto Yang e Feng (2008, p. 813) chamaram de Economia Circular a abreviatura de Ciclo Fechado de Economia de Materiais ou Economia de Recursos Circulados.

O termo Economia Circular, portanto, tem sido associado a uma variedade de significados e associações por diferentes autores, mas o que eles geralmente têm em comum é o conceito de sistema cíclico em malha fechada (Murray, Skene, \& Haynes, 2017). Murray, Skene e Haynes (2017) destacam que o advento da economia em circuito fechado ocorreu pela primeira vez na analogia da Terra da Nave espacial de Boulding (1966). Mais tarde, desenvolvido por Stahel e Reday-Mulvey (1976), que se tornou influente sobre a política alemã e japonesa dos anos 80 e 90 (Triebswetter \& Hitchens, 2005; Moriguchi, 2007; Bilitewski, 2007). Essas políticas, por sua vez, inspiraram a China a instalar a Economia Circular como sua principal estrutura ao aumento do crescimento com danos ambientais menores. Uma diferença interessante entre a Economia Circular e a maioria das outras escolas 
de pensamento sustentável é que ela surgiu em grande parte da legislação (pelo menos no contexto chinês) e não de um grupo de acadêmicos que se separaram de um campo e iniciaram um novo (exemplificado pelo surgimento da Economia Ecológica da Economia Ambiental, conforme descrito por Ropke (2004; 2005). Isso pode explicar por que a Economia Circular ainda não adquiriu um periódico, um conselho editorial e um grupo de faculdades próprias, marcas territoriais normais de um grupo de acadêmicos (Murray, Skene, \& Haynes, 2017).

\section{Economia espiral}

Economia espiral é uma variação atribuída para ao conceito de economia circular. Parte da premissa de que é possível aprender do mundo natural e aplicar isso às nossas organizações e à economia. Os subprodutos de uma organização ou indústria não só formam um componente de outra indústria, mas tornam-se uma plataforma que engendra oportunidades de desdobramentos infinitos em diferentes escalas, bem como a famosa sequência de Fibonacci (Harwood, 2017), que pressupõe que um grupo dedicado de pessoas pode projetar e aproveitar mais tipos de interações e efeitos de rede. As capacidades coletivas na sala de aula, as hastags no twitter e nas demais redes sociais, podem criar espaços de interação que aconteçam em escala e que são notavelmente poderosos (Harwood, 2017).

\section{Cradle to cradle - berço ao berço}

Cradle to Cradle é um conceito de design desenvolvido na década de 1990 por Michael Braungart, William McDonough e os cientistas da EPEA Internationale Umwelt for schung, em Hamburg, Alemanha. O conceito descreve o uso seguro e potencialmente infinito de materiais em ciclos. Cradle to Cradle representa inovação, qualidade e bom design. É um conceito inspirado na natureza, em que os produtos são criados de acordo com os princípios de uma economia circular ideal. Isso diferencia Cradle to Cradle de reciclagem convencional e do conceito de ecoeficiência. O conceito de design Cradle to Cradle é sobre ecoeficácia e vai além das ferramentas e abordagens convencionais de sustentabilidade, que mostram principalmente a influência negativa dos humanos sobre o meio ambiente. O Cradle to Cradle segue a linha do Triple Bottom Line e sua implementação cria benefícios econômicos, sociais e ecológicos iguais (Mcdonough \& Braungart, 2002).

Essa expressão (cradle to cradle) foi título de um livro-manifesto publicado em 2002 pelo arquiteto americano William McDonough e pelo engenheiro químico alemão Michael Braungart, que veio a se tornar uma das obras mais influentes do pensamento ecológico mundial (Mcdonough \& Braungart, 2002).

A economia circular foi apelidada de cradle to cradle, a fim de distinguir, do berço ao túmulo, a abordagem associada ao conceito de análise do ciclo de vida do produto. Esse conjunto de argumentos centra-se no design de objetos manufaturados, em que a desmontagem, adaptação e reutilização são consideradas desde o início. Prevê uma economia baseada no recondicionamento, remanufatura e reciclagem (Gregson et al., 2015). 
O Cradle to Cradle oferece às empresas a oportunidade de apresentar seus produtos não mais apenas para venda, mas disponíveis para uso. Após o uso do produto, os materiais são retirados como parte de um sistema de reprocessamento e, portanto, permanecem em circulação. As empresas podem tornar-se menos dependentes das flutuações de preços nos mercados de matérias-primas. A economia de todo o ciclo de criação de valor é melhorada. O conceito de design Cradle to Cradle também distingue os ciclos biológico e tecnológico dos materiais. Os resíduos de um produto antigo tornam-se o alimento para um novo produto. No ciclo biológico, os materiais são devolvidos à biosfera sob a forma de composto ou outros nutrientes, com base nos quais novos materiais podem ser criados. No ciclo técnico, os materiais que não são utilizados durante o uso do produto podem ser reprocessados para permitir que sejam usados em um novo produto (Mcdonough \& Braungart, 2002).

\section{Logística reversa}

A logística reversa, conhecida também por reversível ou inversa, é a área da logística que trata, genericamente, do fluxo físico de produtos, embalagens ou outros materiais, desde o ponto de consumo até o local de origem. Os processos de logística reversa existem há tempos, entretanto, não eram tratados e denominados como tal. Como exemplos de logística reversa, há: o retorno das garrafas (vasilhame), a recolha/coleta de lixos e resíduos recicláveis. A logística inversa ou reversa aborda a questão da recuperação de produtos, parte de produtos, embalagens, materiais, entre outros, desde o ponto de consumo até o local de origem ou de decomposição em local seguro, com o menor risco ambiental possível (Luttwak, 1971).

Rogers e Tibben-Lembke (1998) definiram a logística reversa como o processo de planejamento, implementação e controle eficiente do fluxo econômico de matérias-primas, inventário em processo, produtos acabados e informações relacionadas ao ponto de consumo bem como ao ponto de origem, com a finalidade de recuperar valor ou disposição adequada. Mais precisamente, a logística reversa é o processo de mover mercadorias de seu destino final típico com o objetivo de recuperar o valor ou disposição adequada (Rogers \& Tibben-Lembke, 1998). De acordo com a Política Nacional de Resíduos Sólidos (estabelecida pela lei 12.305 de 2/08/2010), a logística reversa pode ser definida como "instrumento de desenvolvimento econômico e social caracterizado por um conjunto de ações, procedimentos e meios destinados a viabilizar a coleta e a restituição dos resíduos sólidos ao setor empresarial, para reaproveitamento, em seu ciclo ou em outros ciclos produtivos, ou outra destinação final ambientalmente adequada" (Brasil, 2013).

A história da logística reversa encontra sua raiz na Guerra Civil Americana (Tibben-Lembke \& Rogers, 2002Porém, há outra literatura que registra a história das atividades de logística reversa ainda antes desse período, contudo, tais atividades não foram sistematicamente registradas ou amplamente reconhecidas (Tibben-Lembke's \& Rogers, 2002).

Rogers e Tibben-Lembke's (2000) destacam alguns períodos relevantes à evolução da logística reversa: 
a. 1861-1865: a história da logística reversa tem suas raízes nas forças armadas, no final da Guerra Civil Americana. O general William T. Sherman percebeu que a natureza da campanha de seus exércitos estava associada à oferta e mobilidade e que suas operações em território hostil seriam difíceis. Ele enfrentou a intrincada tarefa de fornecer seus soldados durante a marcha.

b. 1872: o varejo continuou a direcionar a história da logística reversa: as questões de retornos de varejo atuais encontram suas raízes na política de atendimento ao cliente da Montgomery Ward. Montgomery Ward é uma loja de móveis americana estabelecida em 1872. Sua política era se o cliente não estivesse 100\% satisfeito, ele poderia trazer o produto de volta, para um reembolso total.

c. 1942: a guerra sempre cria grandes soluções de logística. A história automotiva do mercado de revenda da logística reversa tem raízes na segunda guerra mundial. A falta de material durante a Segunda Guerra Mundial criou a necessidade de reconstruir as peças dos automóveis e iniciou uma tendência que continua até hoje. Na verdade, isso se tornou um negócio de US \$36 bilhões e "90 a 95 por cento de todos os iniciadores e alternadores vendidos para substituição são remanufaturados" (Rogers \&Tibben-Lembke's, 2000, p.11).

d. 1984: Recuperações bem-sucedidas de produtos começaram a aumentar o uso e a adoção de logística reversa: a próxima grande data de interesse na história da logística reversa foi a crise ocorrida com o Tylenol, em1984. A Johnson \& Johnson juntamente com os Laboratórios McNeil responderam rapidamente quando os Estados Unidos assistiram às notícias da noite sobre o "lote contaminado" de Tylenol. A resposta rápida dos laboratórios da McNeil para retirar os produtos contaminados das prateleiras e rapidamente substituí-los por novos lotes com frascos à prova de inviolabilidade aumentou a credibilidade do público americano e estabeleceu o novo padrão à logística reversa.

e. 1991-1996: mais fiscalização no impacto ambiental positivo da logística reversa vem em 1991. A República Federal da Alemanha aprovou as leis de reciclagem no fluxo ambiental reverso e implementou programas de reciclagem obrigatórios, incluindo disposições para multas e acusações por violadores das diretrizes mais rigorosas ao manuseio e transporte de materiais perigosos, além de responsabilidades para a recuperação de resíduos perigosos. As diretrizes alemãs levaram a uma legislação do Reino Unido de 1996 exigindo que os carregadores e os fabricantes se responsabilizassem pelo retorno e reciclagem dos materiais de embalagem. A União Europeia deu mais um passo, em 2001, ao estabelecer uma meta de 50-65\% de recuperação ou reciclagem de resíduos de embalagens. A implicação para o resto do mundo é que eles devem ser compatíveis se quiserem fazer negócios com a UE.

f. 1998 a 2000: a história da logística reversa é uma aplicação mais estratégica nos negócios. A logística reversa não atraiu muita 
atenção do mundo dos negócios até a última década. No início dos anos 90, o Conselho de Gestão Logística (agora Conselho de Profissionais de Gerenciamento da Cadeia de Suprimentos) publicou dois estudos sobre logística reversa. O primeiro foi escrito por J. R. Stock (1998), que informou sistematicamente sobre como configurar e como operar programas de logística reversa. O livro de Stock (1998) também tentou divulgar o potencial da logística reversa. Rogers e Tibben-Lembke (1998), no entanto, apresentaram uma extensa coleção de vários dados de logística reversa categorizados por tipos industriais. Por exemplo, a indústria de revistas tem os maiores retornos reportados (50\%). As revistas têm uma vida útil curta; se não podem ser vendidas perto da data de publicação/ cobertura, elas devem ser devolvidas ou descartadas. Rogers e Tibben-Lembke (1998) também relataram que outras indústrias com altos retornos médios incluem editores de livros, revendedores de catálogos e empresas de cartões de saudação. Além desses estudos acima mencionados, alguns outros artigos focam a otimização e o gerenciamento da logística reversa para os sistemas de remanufatura e foram publicados em torno do ano 2000.

A definição de logística reversa divulgada pelo Conselho de Gestão Logística evoluiu desde a data do seu reconhecimento. Shad Dowlatshahi (2000), em seu artigo intitulado Developing a Theory of Reverse Logistics, descreveu uma visão holística da logística reversa com 11 fatores. Dowlatshahi (2000) dividiu esses fatores em duas categorias principais: fatores estratégicos e fatores operacionais. Os fatores estratégicos consistem em custos estratégicos, qualidade geral, atendimento ao cliente, preocupações ambientais e preocupações legislativas. Os fatores operacionais consistem na análise do custo-benefício, transporte, armazenagem, gerenciamento de suprimentos, manufatura, reciclagem e embalagem.

O aumento do comércio eletrônico contribui para o aumento da logística reversa. Com o uso da internet e o aumento do varejo multicanal, desde o ano 2000, a logística reversa se tornou um requisito quando se trata de e-commerce. Em meados dos anos 90até 2000, os principais avanços foram no uso comercial da internet. O maior revendedor on-line do mundo, a Amazon, lançada em 1995 como uma livraria on-line, atualmente oferece não só livros, mas DVDs, CDs, downloads de MP3, software, videogames, eletrônicos, vestuário, móveis, alimentos e brinquedos. Quando se pensa em comércio eletrônico, muitas vezes se concentra no ciclo que culmina na entrega de bens a um cliente. Mas a logística reversa se torna inevitável nesse modelo de negócio. Alguns dos aspectos mais comuns que demandam a implementação da logística reversa são: produto que retorna, mercadorias entregues ou não entregues, mercadorias estragadas, má função de mercadorias e programas de intercâmbio. Portanto, a aplicação de logística reversa na indústria de pós-venda é crescente.

Além disso, Vahabzadeh e Yusuff (2015) destacam que o conceito de gerenciamento de retornos havia sido discutido por muitos autores como Terry (1869), Beckley e Logan (1948), e Giultiniane Nwokoye (1975), mas sem associá-lo a fluxos logísticos reversos. Murphy e Poist (1989) usaram o termo 
"Reverse Distribution". Barry, Girard, \& Perras (1993), Carter e Ellram (1998), Jayaraman, Guid Jr.\& Srivastava (1999) empregaram a mesma terminologia. Murphy e Poist (1989) descreveram a logística reversa como o movimento de bens de um consumidor para um produtor em um canal de distribuição. Assim, de acordo com essa definição, a direção dos produtos do cliente para o produtor foi identificada. Já Pohlen e Farris (1992) discutiram sobre o fluxo de bens recicláveis que não vai necessariamente na direção reversa.

\section{Double loop - ciclo duplo}

O conceito de double loop remete a fechar o ciclo ou à modificação de metas ou regras de tomada de decisão à luz da experiência. O aprendizado de loop duplo, preconizado por Argyris (1976), é uma teoria da mudança pessoal orientada para a educação profissional, especialmente para a liderança nas organizações. Foi aplicado no contexto do desenvolvimento da gestão.

Argyris (1976) propõe uma teoria de aprendizado de ciclo duplo que diz respeito a aprender a mudar valores e pressupostos subjacentes. $\mathrm{O}$ foco da teoria é resolver problemas complexos e mal estruturados e que mudam à medida que a resolução de problemas avança. A teoria do duplo circuito baseia-se numa perspectiva de "teoria da ação" delineada por Argyris e Schon (1974). Essa perspectiva examina a realidade do ponto de vista dos seres humanos como atores. Mudanças nos valores, comportamento, liderança e ajuda aos outros fazem parte e são informados pela teoria da ação dos atores. Um aspecto importante da teoria é a distinção entre a teoria adotada de um indivíduo e sua "teoria em uso" (o que eles realmente fazem). Trazer esses dois para congruência é uma preocupação primordial no aprendizado do ciclo duplo. Normalmente, a interação é necessária para identificar o conflito.

Existem quatro etapas básicas no processo de aprendizagem da teoria da ação: (1) descoberta adotada e teoria em uso, (2) invenção de novos significados, (3) produção de novas ações e (4) generalização de resultados. O aprendizado de ciclo duplo envolve a aplicação de cada uma dessas etapas. No aprendizado de ciclo duplo, as hipóteses subjacentes às visualizações atuais são questionadas e as hipóteses sobre o comportamento são testadas publicamente. O resultado final da aprendizagem em ciclo duplo deve ser de maior eficácia na tomada de decisões e melhor aceitação de falhas e erros.

Nos últimos anos, Argyris se concentrou em uma metodologia para implementar a teoria da ação em larga escala chamada "ciência da ação" (Argyris, Putnam. \& Smith, 1985) e no papel da aprendizagem em nível organizacional (por exemplo, Argyris, 1993; Argyris \& Schon, 1996). Chris Argyris (1991) empregou o termo double loop para explicar como se aprende. O aprendizado de ciclo duplo é usado quando é imprescindível mudar o modelo mental que depende de uma decisão. Ao contrário dos loops únicos, esse modelo inclui uma mudança na compreensão, desde a simples e estática até a mais ampla e mais dinâmica, levando em consideração as mudanças nos ambientes e a necessidade de mudanças de expressão em modelos mentais. No aprendizado em um único ciclo, há tentativa repetida de resolver o mesmo problema, sem variação de método e sem nunca questionar o objetivo. 
Para o caso do aprendizado pelo ciclo duplo, Argyris (1991) usou como exemplo o termostato que acende automaticamente. O aquecimento sempre que a temperatura em uma sala cai abaixo de $68^{\circ} \mathrm{F}$ é um bom exemplo de aprendizagem em um único ciclo. Um termostato poderia perguntar: por que estou configurado para $68^{\circ} \mathrm{F}$ ? E então explorar se alguma outra temperatura pode ou não alcançar economicamente a meta de aquecer a sala. Se isso acontecesse, a experiência do termostato permitiria um aprendizado de ciclo duplo. No contexto da sustentabilidade, o conceito passou a ser disseminado pela Ellen MacArthur Foundation a partir do relatório Towards the circular economy, que foi publicado no ano de 2013. Na oportunidade, os termos usados eram closed-loop, restorative loops, inner-loop, circular loop, reverse loop e remanufacturing loop.

\section{Closed-loop- ciclo fechado}

No final da década de 1970, o arquiteto Walter Stahel chegou à conclusão de que o modelo econômico linear atual não é sustentável. Ele baseou-se no fato de que, se as pessoas continuam a aumentar o consumo, haveria grandes problemas no futuro, como destacado pelo Clube de Roma em seu relatório "Limites ao crescimento" publicado em 1972 e que foi citado em Meadows, Meadows, Randers, Behrens III (1973). Este concluiu que o atual modelo de produção econômica não era sustentável devido ao aumento da demanda por matérias-primas em todo o mundo e a acumulação de resíduos. Stahel teve a ideia de fechar os ciclos materiais e reformar a economia. O conceito de fechamento dos ciclos foi estudado e desenvolvido em casos comerciais concretos nos anos seguintes. E resultou no conceito da economia circular, que pode ser definida como: um conceito em que o crescimento e a prosperidade são desacoplados dos recursos naturais, consumo e degradação do ecossistema. Ao abster-se de jogar fora produtos usados, componentes e materiais, optando por reencaminhá-los a fim de gerar valor em outras cadeias de produção, pode-se criar uma sociedade com uma economia saudável, inspirada e em equilíbrio com a natureza.

Portanto, foram Stahel e Reday-Mulvey (1976) que primeiro se referiram a uma economia de ciclo fechado. A ideia de Stahel de durabilidade melhorada foi realmente extraída dos escritos de Boulding (1966, p.12) que escreveu: "Eu suspeito que subestimamos, mesmo na nossa economia, os ganhos de maior durabilidade". Outra reivindicação interessante para uso é de Robert (1991, p.1) que afirmou: "A maioria dos problemas ambientais são baseados no mesmo erro sistêmico, processamento linear de material. Até que os recursos sejam processados em ciclos, seja pela sociedade ou por processos biogeoquímicos, a economia global e a saúde pública continuarão a deteriorar-se ".

\section{Upclycle - ciclo ascendente}

Upcycling é o processo de transformar resíduos ou produtos inúteis e descartáveis em novos materiais ou produtos de maior valor, uso ou qualidade. Além disso, utiliza materiais no final da vida útil, da mesma forma que eles são descartados nos lixo, para dar uma nova utilidade. O upcycling corre no 
processo ao contrário da reciclagem, que usa energia para destruir a forma e então transformar em algo novo. Zimring (2016) conceitua upcycling como a criação de novos bens a partir de bens transformados de uma maneira que aumenta o valor do material, tornando-se moda e forma ambientalmente consciente de design.

De acordo com Zimring (2016), o primeiro registro de uso do termo upcycling foi por Reine Pilz da PilzGmbH, em entrevista para Kay Thornton, da Salvo, 1994, sobre reciclagem. Ele disse, "Eu chamo isso de downcycling. Eles quebram tijolos, concreto, eles quebram tudo. O que precisamos é de upcycling, onde é dado mais valor aos produtos antigos e não menos." (p.11).

O termo upcycling também foi usado por William McDonough e Michael Braungart em seu livro Cradle to Cradle: Remaking the Way We Make Things, de 2002. Eles afirmaram que o objetivo do upcycling é evitar desperdício de materiais potencialmente úteis, fazendo uso dos já existentes. Isso reduz o consumo de novas matérias-primas durante a criação de novos produtos, o que pode resultar em uma redução do consumo de energia, poluição do ar, poluição da água e até diminuição de emissões de gases de efeito estufa.

Upcycling é o oposto do downcycling, que é a outra metade do processo da reciclagem. Downcycling envolve a conversão de materiais e produtos em novos materiais de menor qualidade. Por exemplo, durante o processo de reciclagem de plástico, exceto os usados para criar garrafas, diversos tipos de plásticos são misturados entre si, resultando em um híbrido. Este híbrido é usado em aplicações de madeira plástica. O crescimento de utilização do processo de upcycling deve-se à sua atual aceitação comercial e aos custos reduzidos de materiais reutilizados.

O termo upcycling tornou-se associado às atividades de escala industrial, por exemplo, conforme detalhado pelo arquiteto e químico William McDonoughe Michael Braungart no livro publicado no ano de 2013 The Upcycle: Beyond Sustainability, Designing for Abundance. Nele, McDonough e Braungart descrevem como toda a produção industrial deve ser reconcebida a fim de aumentar o valor dos materiais existentes com o objetivo final de nunca colocar qualquer material de fabricação em sumidouros, bem como evitar criar resíduos tóxicos. O fascínio do upcycling para atacar problemas ambientais associados com o desperdício fez com que seu uso migrasse dos produtores artesanais, como Bally, para grandes corporações. A empresa de calçados Adidas anunciou uma colaboração com a empresa Parrow Cyrill Gutsch, em 2015, para produzir um tênis- um calçado superior feito inteiramente de fios e filamentos recuperados e reciclados de resíduos oceânicos, de redes e malhas ilegais de águas profundas. Parley procura encontrar soluções de design para o problema da poluição plasmática dos oceanos. O upcycling representa esperança para a produção industrial responsável (Zimring, 2016).

Embora esse termo para a eliminação de resíduos, por meio da reutilização de materiais ainda utilizáveis, seja, muitas vezes, visto como inovador de fato, o ato de fabricar bens de maior valor que o material pós-consumidor ou pós-industrial que os compõem tem uma longa história. Tanto quanto a história da reciclagem mergulha mais no passado do que o 
advento dos programas de coleta na era ambiental, o histórico de upcycling deve abranger os métodos e objetivos dos fabricantes que empregam pós-consumo e materiais pós-industriais durante toda a história industrial. Essa lente ilumina como e por que as indústrias reutilizam materiais com maiores considerações de valor e intenção. Tal abordagem pode levar a reapreciar o automóvel fabricado a partir de estradas de ferro em desuso, o arranha-céu feito de edifícios demolidos e até mesmo livros produzidos em massa feitos de trapos. Pode levar a debates filosóficos sobre os valores inerentes a transformar arados em espadas e vice-versa (Zimring, 2016).

O upcycling não é um novo conceito. Alguns dos melhores exemplos de upcycling modernos são da década de 1930 aos 40, quando as famílias tinham poucos recursos econômicos ou materiais. Nessa época, elas reutilizavam itens repetidamente até que não fossem mais úteis: os sacos de alimentação eram transformados em vestidos, as portas antigas eram transformadas na nova mesa da sala de jantar. O que há de novo é novo novamente, mas com um toque. Economia/parcimônia ainda é uma tendência hoje e um grande motivo para algumas pessoas reutilizarem sucessivamente recursos. Outros desfrutam da estética artística, com muitos itens inventados que rivalizam com os encontrados em lojas de departamento de alta tecnologia. Mas um dos maiores motivos para o renascimento do upcycling é o impacto positivo no meio ambiente. Os itens destinados ao despejo são resgatados e refeitos em algo útil. Além disso, o upcycling é uma forma de vida para pessoas em países em desenvolvimento. As matérias-primas são caras para que as pessoas usem o que podem encontrar para criar tigelas, cestas, joias e outros itens úteis e bonitos. O upcycling proporciona um impacto positivo ao meio ambiente. Quando você se envolve, remove itens do fluxo de lixo global. Optar pelo upcycling em vez da reciclagem também é bom. A reciclagem requer energia ou água para quebrar/reconstituir materiais para uso. $\mathrm{O}$ Upcycling requer apenas sua própria criatividade e boa vontade (Hipcycle, 2017).

\section{Simbiose industrial}

Chertow e Park (2016) afirmam que a simbiose industrial é uma derivação/subcampo da ecologia industrial. Envolve, tradicionalmente, indústrias e entidades separadas em uma abordagem colaborativa ao compartilhamento de recursos que beneficia tanto o meio ambiente como a economia. A essência da simbiose industrial é a cooperação, compartilhamento de recursos como água, energia e subprodutos e resíduos de materiais em todas as organizações tanto para o benefício ambiental quanto econômico.

A classificação dos conceitos de simbiose industrial reexamina sua relação com parques eco-industriais e clusters. Quando as ideias se juntam de muitos lugares, tradições e culturas diferentes, há variações maiores e menores em conteúdo e ênfase, mesmo que muitas instituições contemplem a noção de interferência no compartilhamento de recursos. A comunidade empresarial internacional se inclinou para outras expressões, como a sinergia de subproduto, com foco não apenas na interface reutilização de recursos, mas também na reutilização intrafirma (Chertow \& Park, 2016). 
A simbiose industrial, um conceito espacial menos limitado do que o de ecoparques industriais, concentra-se na reutilização de recursos e em como alcançá-los de forma técnica, econômica e comportamental, mais do que na fisicalidade de qualquer site particular, o que, claro, também é muito importante (Chertow \& Park, 2016)

Lombardi e Laybourn (2012) destacam que a simbiose industrial não se refere essencialmente a resíduos localizados e trocas de produtos secundários, nem deve ser confundida com economias de aglomeração ou clusters industriais, em que a proximidade geográfica é condição necessária. Nega-se, explicitamente, o argumento de proximidade geográfica em favor de um que está enraizado em inovação e redes para o compartilhamento de conhecimento. A definição de Chertow (2000) foi proposta com base no conhecimento de simbiose industrial na época, bem antes do estabelecimento do Programa Nacional de simbiose industrial (NISP) nos Estados Unidos.

A definição de simbiose industrial proposta por Chertow (2000, p.313) é: "A parte da ecologia industrial conhecida como simbiose industrial envolve indústrias tradicionalmente separadas em uma abordagem coletiva de vantagem competitiva envolvendo intercâmbio físico de materiais, energia, água e subprodutos". As chaves para a simbiose industrial são colaboração e a possibilidade de sinergia oferecidas pela proximidade geográfica.

A simbiose industrial se refere aos diferentes setores da economia (setores da indústria), propriedade, geografia (instalações), ou função (atividades e processos) e de que forma a simbiose industrial deve ser tratada quando os limites das empresas mudam no tempo, através de fusões, aquisições ou relações de simbiose industrial de longa data (Van Berkel, Fujita, Hashimoto, \& Fuji, \&2009).

Sobremaneira é a indústria o principal foco da simbiose industrial. A indústria é responsável pela mobilização e fluxos de recursos transformadores (Ayres, 1989) e ela é mais adequada para controlar seus processos e subprodutos resultantes. Laybourn (2006) estendeu a definição de Chertow para incluir outras organizações, tornando explícito o envolvimento de parceiros não industriais em uma rede NISP, incluindo pesquisas e organizações governamentais. Organizações acadêmicas e outras organizações de pesquisa foram importantes no co-desenvolvimento das tecnologias inovadoras centrais para certas sinergias: no Reino Unido, uma pesquisa acadêmica identificou novos processos para extrair metais preciosos da varredura de estradas e para recuperar a prata de filmes de raios-x. Colaboração estreita com as autoridades é central à convocação do poder das autoridades e esclarecimento de políticas e regulamentos (Lowe \& Evans, 1995; Lombardi \& Laybourn, 2012), especialmente quando o recurso em questão é rigorosamente regulado.

Um dos pontos principais do conceito de simbiose industrial é a relação mutualmente benéfica entre empresas integrantes de um ecossistema industrial, em que uma empresa aproveita os resíduos de outras empresas como novos insumos para processos produtivos. A ideia de parques industriais com resíduo zero é o ponto de partida do conceito de simbiose industrial. Nesse tipo de iniciativa, gerada principalmente pela pressão exercida pelos custos de disposição de resíduos e regulações ambientais mais restritas, as 
preocupações sobre a degradação ambiental têm levado diversas empresas a rever suas estratégias.

O termo simbiose significa "vivendo junto" e é usado para descrever interações nas quais ocorre o mutualismo, isto é, relacionamentos entre organismos de espécies diferentes, envolvidos em trocas diretas, feitas em prol de benefícios mútuos (Begon, Harper, \& Townsend, 2007; Callenbach, 2001; Pinto-Coelho, 2002). Conforme Begon et al. (2007), as relações mutualistas abrangem bens ou serviços e resultam na aquisição, pelos participantes, de novas capacidades. Conforme Chertow (2000), os elementos-chave para a Simbiose Industrial (SI) são a colaboração e as possibilidades sinérgicas proporcionadas pela proximidade geográfica entre as organizações interessadas. Assim, a SI oferece contribuições relevantes para a El, na medida em que adota e implementa características dos ecossistemas naturais, tais como conectividade, comunidade e cooperação (Costa \& Ferrão, 2010).

Lombardi e Laybourn (2012) expõem a definição de Simbiose Industrial como uma rede composta por diversas empresas para fomentar a ecoinovação e a mudança de cultura em longo prazo. Assim, a SI é definida de maneira a representar um complexo de interações que torne possível desenvolver e compartilhar conhecimentos, gerando transações mutuamente rentáveis e processos de negócios mais eficientes. Para os autores supramencionados, devido ao atual potencial tecnológico, mesmo que a proximidade geográfica seja frequentemente associada com a SI, ela não deve ser considerada como um fator determinante da sua operacionalização.

\section{Life cycle assessment - análise do ciclo de vida}

A Life Cycle Assessment (LCA) é uma ferramenta usada para quantificar os impactos ambientais de um produto ou processo ao longo de seu ciclo de vida - desde a aquisição, fabricação, transporte, montagem, uso e disposição de matérias-primas. Pode ser usada a fim de avaliar os impactos em termos de uma única preocupação ambiental, como mudanças climáticas, ou através de múltiplos impactos ambientais. Dessa forma, as empresas decidem quais estratégias adotar para a redução dos impactos ambientais gerados por seus processos produtivos (GDRC, 2017).

A Análise do Ciclo de Vida (ACV) surgiu na década de 60, na Europa e nos Estados Unidos e foi impulsionada pela crise do petróleo da década de 70 como uma ferramenta para analisar opções para redução de custos operacionais relacionados ao consumo de energia e de matérias-primas de processos produtivos, com o objetivo de buscar fontes alternativas ao uso de combustíveis e materiais de fontes fósseis. Em 1969, a empresa Coca-Cola encomendou um estudo da Midwest Research Institute (MRI) para comparar os diferentes tipos de embalagens de refrigerante e selecionar quais deles eram os mais adequados sob o ponto de vista ambiental e com relação ao desempenho na preservação dos recursos naturais. Nas décadas de 80 e 90, a ferramenta evoluiu para uma avaliação mais completa, com a inclusão de modelos econômicos e de impactos ambientais. Atualmente, também podem ser incluídas as variáveis sociais, formando, assim, os três pilares da sustentabilidade (Chehebe, 1998; Seo \& Kulai, 2006). 
Lucas (2015) destaca que os empresários, na década de 80, começaram a perceber que a preservação da natureza poderia diminuir despesas operacionais, o que contribuiu para alterarem a sua conduta quanto à ocorrência de impactos, passando, então, a investir na adoção de ações de prevenção. As premissas passaram a ser: atender à legislação, evitar ou reduzir a geração de rejeitos e promover o aproveitamento dos rejeitos.

Em 2002, a United Nation Environmental Program (UEP) e a Society of Environmental Toxicology and Chemistry (SETAC) consolidaram uma ação denominada Life Cicle Initiative. Essa iniciativa tratava a ACV por meio de três programas de competência mundial. O primeiro foi denominado Life Cicle Inventory, com foco no desenvolvimento de metodologia para elaboração de inventários ambientais. O segundo foi chamado de Life Cycle Impact Assesment e buscou consolidar a etapa de Life Cycle Management, focando na agregação de uma perspectiva de ciclo de vida às ações essenciais à gestão empresarial, com o propósito de obter aumento da eficiência ambiental de produtos, processos e serviços (Rebitzer, et al.2004; Lucas, 2015).

No Brasil, a ACV é divulgada a partir de 1993 (Seo \& Kulay, 2006). Kulay (2004) afirma que, em 1998, foi registrado um marco na trajetória da ACV no país, via criação do Grupo de Prevenção da Poluição (GP2), da Escola Politécnica da Universidade de São Paulo. No ano de 2002, foi criada a Associação Brasileira do Ciclo de Vida.

A metodologia de ACV é regulamentada pelas normas ISO 14040 e 14044 , enquanto a avaliação dos impactos sociais e dos custos do ciclo de vida (Life Cycle Costing) estão fundamentadas nos conceitos e princípios do Guia do Programa das Nações Unidas para o Meio Ambiente (UNEP) e da Sociedade de Toxicologia e Química Ambiental (SETAC), respectivamente. Segundo a ISO 14.040, ACV é a "compilação de avaliação das entradas, saídas e dos impactos ambientais potenciais de um sistema de produto ao longo do seu ciclo de vida" (p.1). Essa avaliação é feita sobre todos os estágios de ciclo de vida do produto ou processo, desde a aquisição da matéria-prima ou sua geração a partir de recursos naturais até sua disposição final. Como ocorre, por exemplo, desde a extração das matérias-primas, até o momento em que o produto deixa de ter uso e é descartado como resíduo ou é reciclado, passando por todas as etapas intermediárias de manufatura, transporte e consumo. Por essa razão, a ACV é também chamada de "avaliação do berço ao túmulo". A realização da ACV contempla: a) compilação de um inventário de entradas de energia e materiais relevantes inseridos e emissões ambientais; b) avaliação do impacto ambiental associado com entradas e saídas identificadas; c) interpretação dos resultados sobre o impacto do produto ou processo, para melhor nível de informação de tomadores de decisão (GDRC, 2017).

O objetivo de uma ACV é comparar todos os efeitos ambientais associados com produtos e serviços pela quantificação de todas as entradas e saídas de fluxos elementares e avaliar como esses fluxos podem estar associados a impactos ao meio ambiente. Essa informação pode ser usada para melhorar processos, dar suporte às políticas públicas e servir como base para a tomada de decisão. Os procedimentos de ACV são parte das normativas ISO 14.000 de gerenciamento ambiental: ISO 14.040:2006 e ISO 
14.044:2006 (a ISO 14.044 substituiu as versões anteriores da ISO 14.041 até ISO 14.043), no Brasil foram traduzidas como NBR ISO 14.040:2009 e NBR ISO 14.044:2009 (ISO, 2014).

De acordo com a ABNT(2009), a ACV contribui para: a) a identificação de oportunidades para a melhoria do desempenho ambiental de produtos em diversos pontos de seu ciclo de vida; b) a ampliação do nível de informação dos tomadores de decisão para a gestão ambiental na indústria e nas organizações governamentais ou não governamentais; c) a seleção de indicadores de desempenho ambiental relevantes, incluindo técnicas de medição; d) o marketing ambiental (por exemplo, na implantação de um esquema de rotulagem ou na elaboração de uma declaração ambiental do produto).

Pode ser aplicada a qualquer bem ou serviço da seguinte forma: a) produto: serviço, como é o caso do transporte; da informação, por exemplo, programa de computador; b) materiais e equipamentos, isto é, parte mecânica de um motor; c) materiais processados, assim como, lubrificantes; d) serviços: uma atividade realizada em um produto material fornecido pelo cliente, por exemplo, o reparo de um automóvel; uma atividade desenvolvida em um produto inalterável fornecido pelo cliente, como é o caso de uma declaração de rendimento necessária à elaboração de um pedido de restituição de imposto; a entrega de um produto inalterável, ou seja, a transferência de informações em um contexto de transmissão de conhecimento; a criação de ambiência para o cliente, por exemplo, em hotéis e restaurantes (Lucas, 2015).

\section{Interfaces existentes entre os termos}

Desse modo, as interfaces que foram identificadas entre os conceitos descritos neste trabalho podem ser visualizadas na Figura 1. Essa ilustração foi construída com base nas características conceituais descritas na literatura para cada um dos termos analisados. 


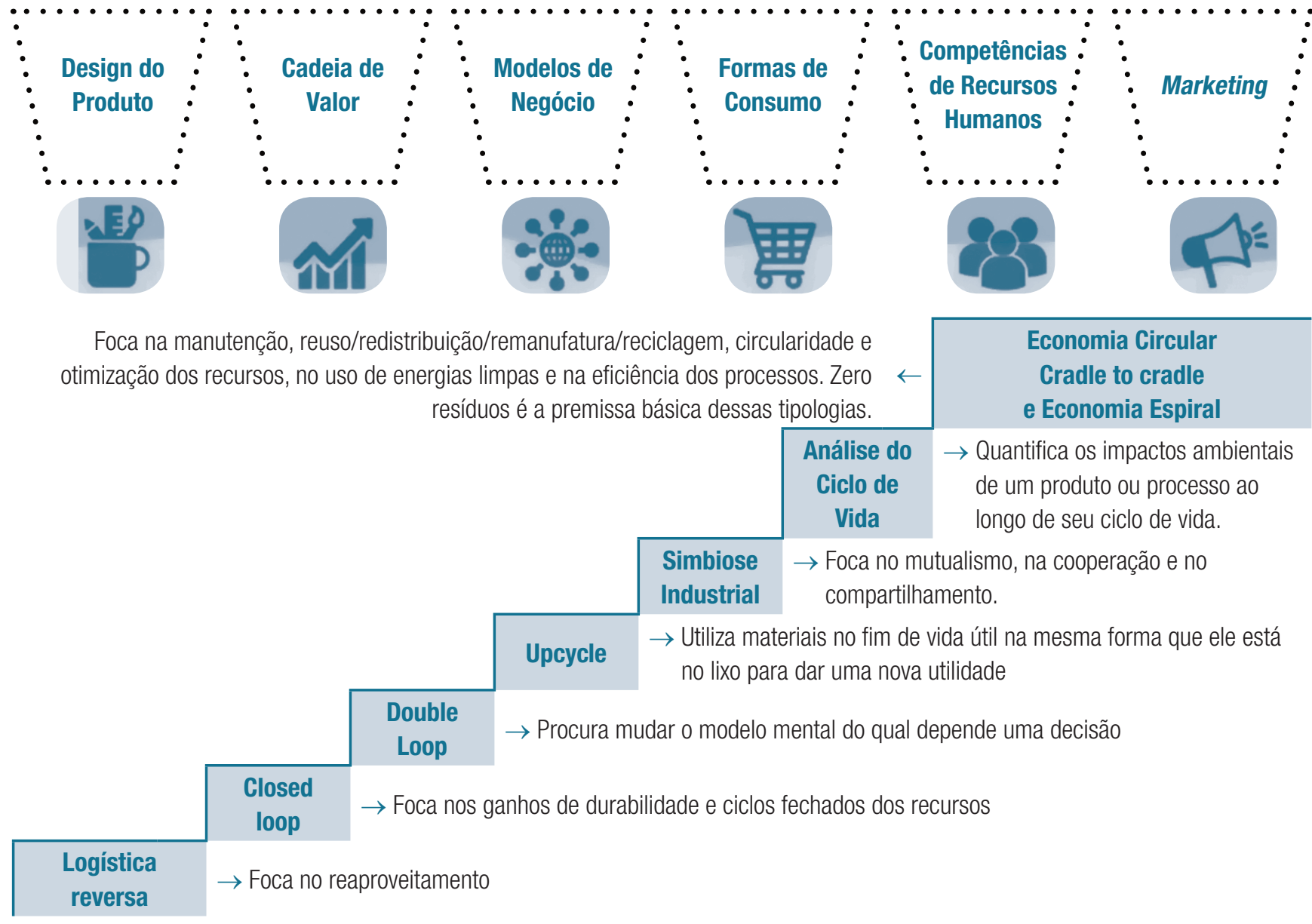

Figura 1: Interfaces entre os conceitos que representam a economia circular Fonte: os autores (2017)

Todos os conceitos descritos na Figura 1 podem ser aplicados em toda a cadeia de valor de um produto ou serviço, desde a sua concepção até a sua destinação final. Entretanto, a complexidade das práticas necessárias à aplicação ao longo de toda a cadeia de produção aumenta, assim como aumenta também a necessidade de inovações que viabilizem o desenvolvimento sustentável. Na percepção dos autores, é possível construir uma escada evolutiva do progresso dos conceitos de produção com base nas práticas de logística reversa, closed loop, double loop, upcycle, simbiose industrial, análise do ciclo de vida, cradle to cradle, economia espiral e economia circular. Entende-se como perspectivas complementares aquelas que possuem interfaces entre si, são aplicadas, muitas vezes, de forma concomitante nas atividades industriais e produzem resultados efetivos à sustentabilidade do planeta. A seguir, o Quadro 1 apresenta as perspectivas analisadas, suas premissas associadas e os benefícios sustentáveis obtidos a partir da sua implantação/adoção. 


\begin{tabular}{|c|c|c|}
\hline Perspectivas & Premissas Associadas & Benefícios Sustentáveis Obtidos \\
\hline $\begin{array}{l}\text { Logística reversa } \\
\text { (foco na gestão de } \\
\text { operações) }\end{array}$ & $\begin{array}{l}\text { - Prima pela coleta e restituição dos resíduos para a } \\
\text { indústria, a fim de que possam ser reintroduzidos na } \\
\text { cadeia de produção ou reaproveitados; } \\
\text { - Atribui responsabilidade compartilhada entre } \\
\text { fabricantes, importadores, distribuidores, } \\
\text { comerciantes, consumidores e dos titulares de } \\
\text { serviços públicos e de limpeza urbana para destinos } \\
\text { reversos de embalagens e produtos; } \\
\text { - Foca no reaproveitamento; } \\
\text { - Produtos são reciclados e remanufaturados pelos } \\
\text { fabricantes. }\end{array}$ & $\begin{array}{l}\text { - Gestão eficiente de resíduos; } \\
\text { - Foco na eficiência do uso dos recursos; } \\
\text { - Reciclagem; } \\
\text { - Eliminação de resíduos; } \\
\text { - Gerenciamento de materiais perigosos; } \\
\text { - Redução de fontes; } \\
\text { - Reutilização de materiais; } \\
\text { - Disposição final; } \\
\text { - Conformidade legal; } \\
\text { - Recuperação de ativos; } \\
\text { - Venda via outlet. }\end{array}$ \\
\hline $\begin{array}{l}\text { Cradle to cradle } \\
\text { (foco na gestão de } \\
\text { operações) }\end{array}$ & $\begin{array}{l}\text { - Os recursos são geridos em uma lógica circular de } \\
\text { criação e reutilização, em que cada passagem de ciclo } \\
\text { se torna um novo berço para determinado material; } \\
\text { - Introduz os sistemas cíclicos, permitindo que recursos } \\
\text { sejam reutilizados indefinidamente e circulem em } \\
\text { fluxos seguros e saudáveis para os seres humanos e } \\
\text { para a natureza. }\end{array}$ & $\begin{array}{l}\text { - Foca na eficácia do uso dos recursos; } \\
\text { - Abstém-se de jogar fora produtos usados, } \\
\text { componentes e materiais, reencaminhando-os para } \\
\text { gerar valor em outras cadeias de produção. }\end{array}$ \\
\hline $\begin{array}{l}\text { Double loop } \\
\text { (ênfase na gestão } \\
\text { do sistema) }\end{array}$ & $\begin{array}{l}\text { - Usa novos modelos e padrões mentais; } \\
\text { - Olha para um resíduo e procura criar alternativas } \\
\text { novas para reintroduzi-lo na cadeia de produção. }\end{array}$ & $\begin{array}{l}\text { - Inovações disruptivas; } \\
\text { - Ecoinovações; } \\
\text { - Progresso em sustentabilidade. }\end{array}$ \\
\hline $\begin{array}{l}\text { Closed loop (foco } \\
\text { na gestão de } \\
\text { operações) }\end{array}$ & $\begin{array}{l}\text { - Preza a circularidade dos recursos; } \\
\text { - Recicla materiais. }\end{array}$ & $\begin{array}{l}\text { - Menos resíduos; } \\
\text { - Menos desperdício; } \\
\text { - Mais qualidade na gestão dos recursos usados nos } \\
\text { processos produtivos. }\end{array}$ \\
\hline $\begin{array}{l}\text { Upcycle (ênfase na } \\
\text { gestão do sistema) }\end{array}$ & $\begin{array}{l}\text { - Usa criatividade e inovatividade; } \\
\text { - Usa novos modelos e padrões mentais; } \\
\text { - Enfatiza contemporâneos de sustentabilidade. }\end{array}$ & $\begin{array}{l}\text { - Segunda utilidade do produto sem necessidade de } \\
\text { reprocessamento; } \\
\text { - Foco na eficiência e na eficácia operacional. }\end{array}$ \\
\hline $\begin{array}{l}\text { Simbiose industrial } \\
\text { (ênfase na gestão } \\
\text { do sistema) }\end{array}$ & $\begin{array}{l}\text { - Foca no mutualismo, na cooperação e no } \\
\text { compartilhamento. }\end{array}$ & $\begin{array}{l}\text { - Pegada ecológica reduzida; } \\
\text { - Otimização de recursos; } \\
\text { - Foco no uso de energias limpas. }\end{array}$ \\
\hline $\begin{array}{l}\text { Análise do Ciclo de } \\
\text { Vida } \\
\text { (foco na gestão de } \\
\text { operações) }\end{array}$ & $\begin{array}{l}\text { - Quantifica os impactos ambientais associados a um } \\
\text { produto ou processo; } \\
\text { - Compila a entrada de energia e materiais relevantes } \\
\text { inseridos e emissões ambientais; } \\
\text { - Desenvolve produtos mais sustentáveis; } \\
\text { - Avalia estratégica de produtos frente a concorrentes; } \\
\text { - Analisa alternativas para redução de impactos dentro } \\
\text { da cadeia de valor; } \\
\text { - Conhece o processo produtivo; } \\
\text { - Faz a gestão de impactos na cadeia produtiva; } \\
\text { - Atende às leis e políticas ambientais (ex.: Política } \\
\text { Nacional de Resíduos Sólidos) } \\
\text { - Melhora a imagem do setor frente à sociedade } \\
\text { (Marketing verde); } \\
\text { - Elabora relatórios de sustentabilidade (ex.: Global } \\
\text { Initiative Reporting - GRI); } \\
\text { - Cria rótulos ambientais (ex.: Declarações Ambientais } \\
\text { de Produto - DAP). }\end{array}$ & $\begin{array}{l}\text { - Mensurabilidade; } \\
\text { - Precisão para calcular ações de compensação do } \\
\text { passivo ambiental gerado; } \\
\text { - Permite calcular o desempenho ambiental da cadeia } \\
\text { de valor. }\end{array}$ \\
\hline
\end{tabular}




\begin{tabular}{|c|c|c|}
\hline Perspectivas & Premissas Associadas & Benefícios Sustentáveis Obtidos \\
\hline $\begin{array}{l}\text { Economia espiral } \\
\text { (foco na gestão do } \\
\text { sistema) }\end{array}$ & $\begin{array}{l}\text { - Enfatiza o ciclo biológico e o ciclo técnicos nos } \\
\text { materiais; } \\
\text { - Prima pela Manutenção do produto; } \\
\text { - Reutiliza/redistribui- produto usado; } \\
\text { - Atualiza/remanufatura o produto; } \\
\text { - Recicla o produto }\end{array}$ & $\begin{array}{l}\text { - Eficiência; } \\
\text { - Eficácia; } \\
\text { - Circularidade dos recursos; } \\
\text { - Otimização dos recursos naturais; } \\
\text { - Uso de energias limpas. }\end{array}$ \\
\hline $\begin{array}{l}\text { Economia circular } \\
\text { (foco na gestão do } \\
\text { sistema) }\end{array}$ & $\begin{array}{l}\text { - Enfatiza o ciclo biológico e ciclo técnicos nos } \\
\text { materiais; } \\
\text { - Prima pela Manutenção do produto; } \\
\text { - Reutiliza/redistribui- produto usado; } \\
\text { - Atualiza/remanufatura o produto; } \\
\text { - Recicla produto. }\end{array}$ & $\begin{array}{l}\text { - Eficiência; } \\
\text { - Eficácia; } \\
\text { - Circularidade dos recursos; } \\
\text { - Otimização dos recursos naturais; } \\
\text { - Uso de energias limpas. }\end{array}$ \\
\hline
\end{tabular}

Quadro 1: Perspectivas sustentáveis, antecedentes e efeitos positivos

Fonte: os autores (2017)

O Quadro 1 sintetiza as principais premissas e benefícios das perspectivas sustentáveis analisadas. Como há uma interface clara entre elas, naturalmente identificam-se características comuns, ou seja, uma sobreposição de características e benefícios. A essência de cada perspectiva pode ser identificada nas premissas e benefícios descritos no Quadro 1. Nota-se que a constante adaptação, regeneração, recriação e inovação em termos de práticas sustentáveis gera conceitos que agregam e congregam elementos que têm o potencial para produzir efeitos substantivos sobre a sustentabilidade. O uso dessas práticas, ao longo do tempo, gera resultados positivos ao meio ambiente, à sociedade, bem como à cultura dos povos. Sobretudo, impacta na dimensão econômica, tão valorada pela sociedade capitalista e industrial.

Outrossim, fica evidente que algumas das perspectivas analisadas têm um foco maior na gestão de operações e de cadeias, enquanto outras direcionam a discussão para sistemas, não somente sistemas de produção, mas sistemas biológicos. A complementaridade e sobreposição existente entre tais perspectivas contribui para criar uma visão sinérgica e sistêmica de uma cadeia de produção, na qual os ganhos podem ser compartilhados entre todos os elos, gerando resultados às empresas e à sociedade.

\section{Considerações finais}

Este artigo tem o objetivo de contribuir para esclarecer aspectos conceituais relacionados a conceitos e termos técnicos que costumeiramente são utilizados no ambiente acadêmico e empresarial. Além disso, apresenta um framework que ilustra as interfaces existentes entre os conceitos e perspectivas analisadas. Desse modo, entende-se que, para os pesquisadores, é oportuno esclarecer e destacaras diferenças semânticas e conceituais dos termos analisados.

Essa base conceitual pode ser útil aos pesquisadores e gestores que se identificam com a temática economia circular. Estudos futuros poderiam identificar e analisaras diversas metodologias e ferramentas que podem ser 
utilizadas para operacionalizar as perspectivas aqui descritas, assim como identificar as teorias organizacionais que podem ser utilizadas a fim de compreender o contexto de adoção/implantação de práticas de economia circular. Por exemplo, em países desenvolvidos e em desenvolvimento, em países comprometidos com as diretrizes de sustentabilidade promulgadas pela ONU e também por aqueles países que adotam diretrizes sustentáveis de modo reativo.

As implicações ao campo de pesquisa estão associadas, em especial, para a economia circular no Brasil. Consensualmente, a área de operações e também os gestores apropriam-se dos termos em inglês, todavia, nem sempre encontram uma tradução apropriada para disseminação de tais termos na literatura nacional. Desse modo, o artigo em questão fez um exercício de apresentar traduções que podem ser usadas na literatura nacional. Além disso, busca contribuir também em evidenciar as origens conceituais, diferenças e similaridades existentes entre os termos analisados. Essa informação pode ser útil para gestores e consultores disseminarem nas empresas e mostrarem o quanto o conhecimento da literatura pode contribuir à tomada de decisões relacionadas às melhores técnica e práticas a serem adotadas na cadeia de produção com o intuito de promoverem a sustentabilidade.

Os pesquisadores brasileiros também podem beneficiar-se dos resultados deste estudo e avançar em termos de estudos aplicados, a exemplo do mapeamento de organizações adotantes de cada uma das práticas, além de estudos sobre impactos na eficiência operacional dentro das organizações adotantes. Os gestores públicos podem usar as diferentes tipologias aqui apresentadas com o propósito de proporem políticas públicas que contribuam para o progresso da sustentabilidade nas organizações e para a ampliação da circularidade dos recursos nos processos produtivos.

Estudos futuros podem também contribuir para consolidar os temas e evidenciar potencialidades e fragilidades de cada uma das perspectivas apresentadas. A aplicabilidade das evidências do nosso estudo nas organizações e o monitoramento das barreiras à ampla consolidação podem gerar conhecimentos relevantes à tomada de decisão dos gestores públicos e organizacionais, consequentemente, à economia e sociedade brasileiras.

\section{Referências}

Abnt - Associação Brasileira de Normas Técnicas (2009). NBR ISO 14.040: Gestão Ambiental - Avaliação do Ciclo de Vida - princípios e estrutura. Rio de Janeiro.

Alexander, C., \& Reno, J. (2012). Economies of recycling: the global transformation, values and social relations. London: Zed Books.

Argyris, C. (1991). Teaching smart people how to learn. Harvard Business Review, 69(3), 99-109.

Argyris, C. (1976). Increasing Leadership Effectiveness. New York: Wiley.

Argyris, C. (1993). On Organizational Learning. Cambridge. MA: Blackwell.

Argyris, C., \&Schon, D. (1974). Theory in Practice. San Francisco: Jossey-Bass. 
Argyris, C. (1982). Reasoning, Learning and Action. Individual and Organizational. San Francisco: Jossey-Bass.

Argyris, C. (1993). Knowledge for Action. San Francisco: Jossey-Bass.

Argyris, C., Putnam, R., \& Smith, D. (1985). Action Science. San Francisco: Jossey Bass.

Argyris, C., \& Schön, D. A. (1996). Organizational learning II: Theory, method and practice. Reading, MA: Addison-Wesley.

Ayres, R. U. (1989). Industrial metabolism: Theory and Policy. In Ausubel, J. H., \& Sladovich, H. E (Ed.). Technology and the environment. Washington, DC: National Academy Press.

Barry, J., Girard, G., \& Perras, C. (1993). Logistics planning shift into reverse. Journal of European Business, 5(1), 34-38.

Beckley, D. K., \& Logan, W. B. (1948). The retail sales person at work. New York: Gregg publishing.

Begon, M., Harper, J. L., \& Townsend, C. R. (2007). Ecologia: de indivíduos a ecossistemas. Porto Alegre: Artmed.

Bilitewski, B. (2007, October). Circular Economy in Germany. Eleventh International Waste Management and Landfill Symposium, Cagliari, Italy, 1-5.

Boulding, K.E. (1966). The Economics of the Coming Spaceship Earth. In Jarrett, H. (Ed.) Environmental Quality in a Growing (pp. 3-14). Baltimore, MD: Resources for the Future/Johns Hopkins University Press.

Bras, B., \& Mcintosh, M. (1999). Product, process and organizational design forre-manufacture: An overview of research. Robotics and Computer-Integrated Manufacturing, 15(3), 167-178.

Callenbach, E. (2001). Ecologia: um guia de bolso. Peirópolis, São Paulo, SP.

Carson, R. (1962). Silent spring. Cambridge, MA: Riverside.

Carter, C. R., \& Ellram, L. M. (1998). Reverse logistics: A review of the literature and framework for future investigation. Journalof Business Logistics. 19(1), 85-102.

Chehebe, J.R.B. (1998). Análise do ciclo de vida de produtos: ferramenta gerencial da ISO 14.000. Rio de Janeiro: Qualitymark.

Chertow, M. R. (2000). Industrial symbiosis: Literature and taxonomy. Annual Review of Energy and the Environment, 25(1), 313-337.

Chertow, M., \& Park, J. (2016). Scholarship and Practice in Industrial Symbiosis: 1989-2014. In: Clift, R., Druckman A. (Eds.). Taking Stock of Industrial Ecology (pp.87-116). Berlin: Springer.

Cooper, T. (2005). Slower consumption: Reflections on product life spans and the 'throwaway society. Journal of Industrial Ecology, 9(1-2), 51-67.

Cooper, T. (2010). Longer lasting products: Alternatives to the throwaway society. London: Gower.

Costa, I., \& Ferrão, P. (2010). A case study of industrial symbiosis development using a middle-out approach. Journal of Cleaner Production, 18(10-11), 984-922. https:// doi.org/10.1016/j.jclepro.2010.03.007 
Dowlatshahi, S. (2000). Developing a Theory of Reverse Logistics. Interfaces, 30(3), 143-155.

Eco-Innovation Observatory (2011). The eco-innovation challenge: Pathways to a resource-efficient Europe. Recuperado em 7 dezembro, 2017, de https://www.ecoinnovation.eu/index.php/reports/annual-reports?...eco-innovation-challenge

Ellen Macarthur Foundation (2017). Circular Economy implementation in China. Recuperado em 7 dezembro, 2017, de https://www.ellenmacarthurfoundation.org/ news/circular-economy-implementation-in-china

Ellen Macarthur Foundation (2017). Towards the Circular Economy: economics and business rationale for an accelerated transition. Recuperado em 7 dezembro, 2017, de https://www.ellenmacarthurfoundation.org/news/circular-economyimplementation-in-china

Ellen Macarthur Foundation (2017). Rumo a economia circular: o racional de negócio para acelerar a transição. Recuperado em 7 dezembro, 2017, de https://www. ellenmacarthurfoundation.org/news/circular-economy-implementation-in-china

Ellen Macarthur Foundation (2017). What is a circular economy? Recuperado em 7 dezembro, 2017, de https://www.ellenmacarthurfoundation.org/circular-economy

Frosch, R., \& Gallopoulos, N. (1989). Strategies for manufacturing. Scientific American. 261(3), 94-152.

Geng, Y., \& Doberstein, B. (2010). Developing the circular economy in China: Challenges and opportunities for achieving leapfrog development. International Journal of Sustainable Development and World Ecology,15(3), 231-239.

Georgescu-Roegen, N. (1971). The entropy law and the economic process. Cambridge, MA: Harvard University Press.

Giultinian, J. P., \& Nwokoye, N. G. (1975). Developing distribution channels and systems in the emerging recycling industries. International Journal of Physical Distribution, 6(1), 28-38.

Gregson, N., Crang, M, Fuller, S, \& Holmes, H. (2015). Interrogating the circular economy: the moral economy of resource recovery in the EU. Economy and Society, 2(44), 218-243.https://doi.org/10.1080/03085147.2015.1013353

Harwood, R. (2017). Towards a spiral economy. Recuperado em 10 agosto, 2017, de https://www.100open.com/towards-a-spiral-economy/

Hipcycle. (2017). What is Upcycling, Anyway? Recuperado em 10 agosto, 2017, de https://hipcycle.com/what-is-upcycling

ISO - International Organization for Standardization. (2014). Environmental management - Life Cycle Assessment - Principles and framework. Recuperado em 15 agosto, 2017, de https://www.iso.org/standard/37456.html

Jacobsen, B. N. (2006). Industrial symbiosis in Kalundborg, Denmark: a quantitative assessment of economic and environmental aspects. Journal of Industrial Ecology, 10(1-2), 239-258. https://doi.org/10.1162/108819806775545411

Jayaraman, V., Guid Jr., V.D. R., \&Srivastava, R. (1999). A closed-loop logistics model for remanufacturing. Journal of the Operational Research Society, 50(5),497-508. https://doi.org/10.1057/palgrave.jors.2600716 
Kulay, L. (2004). Uso da Análise de Ciclo de Vida para a comparação do desempenho ambiental das rotas úmidas e térmicas de produção de fertilizantes fosfatados. Tese de doutorado, Escola Politécnica, Universidade de São Paulo, USP, São Paulo.

Lancaster, M. (2002). Principles of sustainable and green chemistry. In: Clark, J., \& Macquarrie D. (Eds.). Handbook of Green Chemistry and Technology. Oxford: Blackwell.

Laybourn, P. (2006). The development of the National Industrial Symbiosis Programme (NISP) - A case for publicly funded macro industrial symbiosis networks. Presentation to Intellegant: Made for the Future, Cambridge, UK, 12 March 2006.

Laybourn, P., \& Morrissey, M. (2009). National Industrial Symbiosis Programme: The pathway to a low carbon sustainable economy. Kings Norton, UK: International Synergies Ltd.

Lei $n^{\circ}$ 12.305, de 2 de agosto de 2010. Recuperado em 13 agosto de 2017, de http://www.planalto.gov.br/ccivil_03/_ato2007-2010/2010/lei/112305.htm

Lombardi, R., \& Laybourn, P. (2012). Redefining Industrial Symbiosis: Crossing Academic-Practitioner Boundaries. Journal of Industrial Ecology, 16(1), 28-37. https://doi.org/10.1111/j.1530-9290.2011.00444.x

Lowe, E. A., \& Evans, L. K. (1995). Industrial ecology and industrial ecosystems. Journal

Of Cleaner Production, 3(1-2), 47-53.

Lucas, K.R.G. (2015). Avaliação do ciclo de vida do óleo de girassol. Dissertação de mestrado, Programa de Pós-Graduação em Bioenergia, Londrina, PR, Brasil.

Luttwak, E. (1971). A dictionary of modern war. New York: Harper \& Row.

Mathews, J. A., \& Tan, H. (2011). Progress towards a circular economy in China: The drivers (and inhibitors) of eco-industrial initiative. Journal of Industrial Ecology, 15, 435-457. https://doi.org/10.1111/j.1530-9290.2011.00332.x

Mcdonough, W., \& Braungart, M. (2013). The upcycle: beyond sustainability designing for abundance. New York: Melcher Media.

Mcdonough, W., \& Braungart, M. (2002). Cradle to cradle: remaking the way we make thinks. China: Melcher Media.

Meadows, D. H.; Meadows, D. L.; Randers, J.; Behrens III, W. W. (1973). Limites do Crescimento: Um relatório para o projeto do Clube de Roma sobre o dilema da humanidade. São Paulo: Editora Perspectiva.

Moriguchi, Y. (2007). Material flow indicators to measure progress toward a sound material-cycle society. Journal of Material Cycles and Waste Management, 9(2), 112120.https://doi.org/10.1007/s10163-007-0182-0

Murphy, P. R., \& Poist, R. P. (1989). Managing of logistics retromovements: an empirical analysis of literature suggestions. Transportation Research Forum, 29(1), 177-84.

Murray, A., Skene, K., \& Haynes, K. (2017). The Circular Economy: An Interdisciplinary Exploration of the Concept and Application in a Global Context. Journal of Business Ethics. 3(140), 369-380. https://doi.org/10.1007/s10551-015-2693-2

Pearce, D. W., \& Turner, R.K. (1990). Economics of natural resources and environment. Londres: Harvester Wheashealf. 
Pinto-Coelho, R. M. (2002). Fundamentos em ecologia. Porto Alegre: Artmed.

Pohlen, T. L., \& Farris, T. (1992). Reverse logistics in plastics recycling. International Journal of Physical Distribution \& Logistics Management, 22(7), 35-47.https://doi. org/10.1108/09600039210022051

Rebitzer, G, Ekvall, T., Frischknecht, R., Hunkeler, D., Norris, G., Rydberg, W., Schmidt, W.P., Suh, S., Weidema, B.P., \& Pennington, D.W. (2004). Life cycle assessment. Framework goal and scope definition, inventory analysis and applications. Environment International, 5(30), 701-720. https://doi.org/10.1016/j.envint.2003.11.005

Robert, K. H. (1991). The physician and the environment. Reviews in Oncology. European Organisation for Research and Treatment of Cancer, 4(2), 1-3.

Rogers, D. S., \& Tibben-Lembke, R. S. (1998). Going Backwards: Reverse Logistics Trends and Practices. University of Nevada, Reno.

Ropke, I. (2004). The early history of modern ecological economics. Ecological Economics, 50(1), 293-314. https://doi.org/10.1016/j.ecolecon.2004.02.012

Ropke, I. (2005). Trends in the development of ecological economics from the late 1980s to the early 2000s. Ecological Economics, 55(2), 262-290. https://doi. org/10.1016/j.ecolecon.2004.10.010

Seo, E. S. M., \& Kulay, L. (2006). Avaliação do Ciclo de Vida: ferramenta gerencial para tomada de decisão. Revista de Gestão Integrada em Saúde do Trabalho e Meio Ambiente, 1(1), 1-23.

Stahel, W. R., \& Reday-Mulvey, G. (1976). Jobs for tomorrow: The potential for substituting manpower for energy. DG Manpower, Brussels, European Commission. New York: Vantage Press.

Stock, J. (1998). Development and implementation of reverse logistics programs. Oak Brook: Council of Logistics Management.

Su, B., Heshmati, A., \& Geng, Y. (2013). A review of the circular economy in China: moving from rhetoric to implementation. Journal of Cleaner Production,42(1), 215227.https://doi.org/10.1016/j.jclepro.2012.11.020

Terry S.H. (1967). The retailer's manual, Jennings Brothers. New York: Newark 1869. The Global Development Research Center (2017). Defining Life Cycle Assessment. Recuperado em 15 agosto, 2017, de http://www.gdrc.org/uem/lca/lca-define.html

Tibben-Lembke, R. S., \& Rogers, D. S. (2002). Differences between reverse and forward logistics in a retail environment. An International Journal of Supply Chain Management,7(5), 271-282. https://doi.org/10.1108/13598540210447719

Triebswetter, U., \& Hitchens, D. (2005). The impact of environmental regulation on competitiveness in the German manufacturing industry: A comparison with other countries of the European Union. Journal of Cleaner Production, 13(7), 733-745. https://doi.org/10.1016/j.jclepro.2004.01.009

Vahabzadeh, A. H., \& Yusuff, R. B. M. (2015). A Content Analysis in Reverse Logistics: A review. Journal of Statistics and Management Systems, 4(18), 329-379. https:// doi.org/10.1080/09720510.2014.927605

Van Berkel, R., T.; Fujita, S., Hashimoto, S., \& Fuji., M. (2009). Quantitative assessment of urban and industrial symbiosis in Kawasaki, Japan. Environmental Science \& Technology, 43(5), 1271-1281. http: //doi.or/10.1021/es803319r 
Webster, K. (2015). The circular economy: a wealth of flows. United Kingdom: Ellen MacArthur Foundation Publishing.

Yang, S., \& Feng, N. (2008). A case study of industrial symbiosis: Nanning Sugar Co., Ltd. in China. Resources, Conservation and Recycling, 52(5), 813-520. https://doi. org/10.1016/j.resconrec.2007.11.008

Youtube (2017). Cradle to Cradle: o conceito da economia circular. Recuperado em 17 maio, 2017, de https://www.youtube.com/watch?v=ij3Elbc6otQ

Yuan, Z.W., Bi, J., \& Moriguichi, Y. (2006). The Circular Ecology: A New Development Strategy in China. Journal of Industrial Ecology, 10(1-2), 4-8. https://doi. org/10.1162/108819806775545321

Zang, H.M. (2006). The Research on Theory of Governance and Application in the Circular Economy of Urban. Ph.D Dissertation, Tongji University, Shanghai, China.

Zimring, C. A. (2016). Upcycling in History: Is the Past a Prologue to a Zero-Waste Future? The Case of Aluminum. RCC Perspectives: Transformations in Environment and Society, 3, 45-52. https://doi.org/10.5282/rcc/7542. 